\title{
Bedroom Politics, the Social Media Ulcer: An application of the unhu/ubuntu Philosophy in light of the Technological Determinism and Cultural Imperialism Theory.
}

\author{
Innocent Fungai Chiyadzwa ${ }^{1}$ and Dr Edmore Dube ${ }^{2}$ \\ ${ }^{I}$ (Department of English and Media Studies, Great Zimbabwe University, Zimbabwe) \\ ${ }^{2}$ (Department of Philosophy and Religious Studies, Great Zimbabwe University, Zimbabwe)
}

\begin{abstract}
This paper strove to ascertain whether local social media platforms that focus on dating and sex issues are eroding the cultural values and norms of the Shona people and the push factors for such uses. While it is unprecedented that the developing countries have been importing hardware and software from advanced countries, the implications this has on social values and norms is worth an academic enquiry. The empowering, liberative and emancipatory nature of the internet and social media is undoubted when it comes to the enhancement of democratic participation and diversity of views in the "electronic public sphere," it is the uncontrolled content production's consequences for the humanness and moral value of the Zimbabwean community that is at stake. The study has made use of the Lurking Garanyanya, the Technological Determinism and Cultural Imperialism Theories in its application of the unhu/ubuntu philosophy in an academic endeavour to determine the user-friendly nature of the social media with regards the Shona conception of 'bedroom politics.' The enquiry has established that issues dealing with sexuality have for time immemorial been a private matter and public reference to sexuality is anathema to the Zimbabwean audience.
\end{abstract}

Key Words: Lurking Garanyanya, state of nature, unhu/ubuntu, Cultural Imperialism, social media

\section{Introduction}

The new media and the internet brought with it exciting new opportunities for humanity especially in relation to freedom of association and expression. While this is plausible, the technology also came with threats to the morals of the society as anti-social and anarchy-loving individuals are causing mayhem without shame on social media. The crisis of technological abuse affects the third world mostly, as they are ever adapting to western developed innovations as well as uses of these technologies, thereby leading to a cultural conflict that results in the third world countries' disadvantage. While unprecedentedly new media and social media brought relief in terms of democratic participation other spheres of socio-cultural life that requires utmost privacy became public with issues previously regarded as secret being exposed and thrown into the public arena. The effects of adapting to technological innovations and uses to the unhu/ubuntu philosophy of the Shona people justifies the academic enquiry of this paper.

\section{Hypothesis}

The unhu/ubuntu philosophy, the epicentre of the throbbing indigenous lifeline, is inhibited by the removal of controls which are the vanguard of its very being. There is certainly no symbiotic relationship between individualistic democracy and unhu/ubuntu philosophy which thrives on collective responses to moral aughts and communal responsibility in times of crisis.

\section{Justification}

No man lies comfortably on his laurels when his very wellbeing is under threat from a threatening situation. The proverb of manhood has it that 'kufa komurume kubuda hura' (a heroic man fights until he drops dead). It has emerged that the very core of African existence is under siege from the technological and cultural imperialism. The technological determinism and cultural imperialism have been turning the nuts of unhu / ubuntu in an anticlockwise direction leaving the steadying bolts (taboos) loose and yawning. The very radar of unhu/ubuntu philosophy (rules of respect) has been turned off sardonically brushing aside the secrecy of bedroom politics as mere superstition and backwardness. The social media is awash with pornography which knows no social boundaries or how defamatory nude figures of public officials are. This paper seeks to propose possible remedies to the cultural erosion. 


\section{TheLurkingGaranyanyaTheory}

The Oxford Advanced Learners' Dictionary [1] defines something 'lurking' as that which stays "hidden, especially when waiting to attack or appear," for example, thoughts that "stay in the back of one's mind."Garanyanya refers to a "big, deadly [creature]," "especially a snake" (Standard Shona Dictionary[2]).The Lurking Garanyanya (deadly creature) Theory deals with the state of every human being as generally social, but intermittently exuding a recession into a dangerous, often ecstatic or sardonic behaviour. This happens once social controls have been consciously removed by a controlling power as in jambanja (induced political violence), or unconsciously allowed to lapse or loosen by a coarse situation. The enforcement of controls is essential since human beings naturally dislike direction, enjoy laxity and must be coerced to observe the norm (D. McGregor in S. P. Robbins 1993, 208 [3]).

The dangerous behaviour emanates from a kind of vital force which is always lurking in the background, waiting to pounce on the individual at any opportune moment. After the heat of such a moment the individual recalls one's social obligations and naturally says, "What have I done?" This means the uncontrollable seizure by the force here pictorially presented as a deadly serpentine creature may be unplanned yet quite spontaneous and dangerous. Although Thomas Hobbes dealt with political philosophy his views are quite handy in the present discussion (Hobbes T., Leviathan, 1651[4]).

Thomas Hobbes (1588-1679), the English philosopher, scientist and historian, viewed government as primarily a mechanism for collective security. The social contract gives the sovereign or ruling elite the mandate to protect all (Encyclopaedia Britannica; Thomas-Hobbes: htm [05/06/2013 [5]). Hobbes saw "the state of nature" (symbolically the garanyanya state) as characterized by insecurity caused by continual brutish fighting resulting in violent death, short life and loneliness (The Primate Diaries: The Politics of human Nature: Thomas Hobbes [the politics of human nature Thomas Hobbes - the primate Diaries.htm [6]). The state of nature therefore is a state of chaos. The assumption is, without a strong sanctioning force, the lurking garanyanya comes to the fore and rules the roost. Hobbes is therefore concerned with "the problem of social and political order: how human beings can live together in peace and avoid the fear of civil conflict" (Williams G., The Internet Encyclopaedia of Philosophy: A Peer Reviewed Academic Resource 05/06/2013 [7]).

Once the controls disappear the human beings become suddenly self-interested/egoistic and dangerously gullible. The wickedness of the bad men compels the good men to take recourse for their own protection (De Cive, Epistle Dedicatory [8]). In the state of nature, "the notions of right and wrong, justice and injustice have no place" (Leviathan xiii, 13 [9]) and we can have a right to everything, "even to one another's body" (Leviathan xiv, 4 [10]).

The argument here is that without the rule of law, there emerges a free for all situation; valueless for its public vendetta and the public washing of dirty linen, as the bond of unhu/ubuntu philosophy is lost to the winds. The uncontrolled social media has just provided that scenario as seen in the sardonic postings on the net. The African philosophy (unhu/ubuntu) notes that the reality of the communal world takes precedence over the individual realities (Wright R. A. ed 1984, 171, African Philosophy [11]). Dube (2013, 30-41 [12]) notes that, after birth the individual goes through different rites of incorporation, including those of initiation at puberty, before becoming a full person in the eyes of the community. Through the process of initiation the social contract of moral aughts is brought to bear on the individual and the garanyanya is kept in abeyance and lurking as it is not possible to eliminate or destroy it. Unhu/ubuntu only suppresses and controls it.

In each society there exists communal thought on various issues of philosophic significance (Oruka $\mathrm{H}$. O. 1994, Philosophy Humanity and Philosophy [13]). In Zimbabwe issues on sexuality were traditionally not in the public domain, but the social media has removed all boundaries thereby subverting the normative institution traditionally crafted to deal with the issues in the private domain. The lurking garanyanya has broken the bonds of taboos and has thrown the confidential issues into the electronic public sphere like confetti.

\section{Sexuality Among the Shona People of Zimbabwe}

Behaviour is the crux of Shona education and Aschwanden (1982, 42 [14]) notes that, for the Karanga, 'education' meant "to learn to behave well" with the "inter-humane aspect of education" of paramount importance. Aschwanden (1982, 43 [15]) stresses the importance of strict controls to enforce the right behaviour by quoting the proverb which says: "The father that hides his stick hates his child - Baba vanoviga rushamu vanovenga mwana wavo." The boys and girls were prepared separately for their different tasks in life. For the Remba the young are physically removed from society and are taught in seclusion for at least a month, after which they graduate with new names (Dube 2013, 30-41[16]). During the secluded esoteric instruction the tuba/terere (the Remba whippy stick of authority) is used to enforce strict adherence to the teachings of the senior instructor called nyamukanga. For other Shona groups the young are taught within the home during the performance of separate chores.

This education stresses that sexual organs "are taboo, they must not be looked at or named. If someone uses direct expression in public, he may, in certain circumstances, be brought to trial" (Aschwanden, 1982, 49- 
50 [17]). The young are taught to use figurative language such as referring to a male organ as a fruit. When boys and girls are taught separately they are taught to use this figurative language in a coded manner so that reference to obscenities by one sex group may not offend the other sex group. The women could refer to the uterus as the 'pot' and menstruation as "kugara nguo yembudzi" (Aschwanden, 1982, 90 [18]). In his discussion of the Sadiki Remba esoteric teachings Dube (2013, 35 [19]), notes that, "This teaching is done in coded language. The initiates are expected to communicate in coded language in the presence of shuvuro (uninitiated). The secrets of the clan are passed on from generation to generation in this coded language called Chiremba (the Remba language)."

As a sequel the presentation prayer offered by the nyamukuta (traditional midwife) for the new born runs thus:

"He will be a tough and protective crossbar (husband),

The door that comes in, in good time (erotic),

The door (husband) whose hinge-pin (penis) is accurate..."(Dube, 2013, 30 [20])

And for the female babies the following is said:

"She will mature into a proper door-step (wife/woman),

A door step (woman) that respects the beaten floor (aunts),

A tough hut-roof (woman) resistant to winds (destructive forces)... "(Dube, 2013, 30f [21])

In this manner the child is symbolically made to submit to the dictates of his people. And as it comes out the clan looks forward to seeing the child grow into a great embodiment of its beliefs and practices. It is important to note here that the use of the coded language is to create a private sphere in a public setting. An uninitiated bystander will not be cognitively drawn into the argument and as a result will not be offended by the lucid reference to obscenities.

In order to break the kernel of seclusion one has to be initiated into the particular sex group, which only teaches coded language in respect to the particular sex group. As a seal for joining the relevant same sex group one receives a circumcision mark. "Before the possession of the mark of circumcision and learning of the secrets of the Remba society, one is still regarded as an infant, and is excluded from taking part in matters of importance." (Dube, 2013, 32f [22])

To keep the age groups running "whenever a sizeable number of potential initiates is realised in the village, steps are taken to authorise the circumcision rite. A place with water and vegetation cover is chosen outside the village. Here a musasa (circumcision camp) is built. After this the candidates start coming in with their midhabhi (circumcision sponsors)."(Dube, 2013, 33 [23])

To enforce the exclusive nature of the teaching "Any truant who finds himself in the camp is beaten to death with whippy sticks called tuba or terere, whose sound is distinguishable from that of the common fibre whip. The tuba can either be a curly branch of Munyadza or Mukambamasani tree... The tuba which is also a symbol of order, denotes that one is now a custodian of the Remba tradition and custom."(Dube, 2013, 35f [24]).

The female circumcision which is done within the village follows the line of apprenticeship. The neophyte secretly joins a reputable family of her choice and remains there until she is fully instructed.

All this initiation and use of coded language is done in conjunction with the use of maternal and paternal aunts and uncles in the public and private spheres. Across the Zimbabwean indigenous traditions and cultures the use of such structures has been invaluable for time immemorial. The values of such a system are interred in the utilisation of compact social structures, which are prevalent in immobile societies. The indigenous societies encouraged marriages among vematongo (literally those of shared ruins, but idiomatically, those well known to $u s$ ). This exclusive cultural model despised marriage unions with strangers. The security and dignity of society was in shared traditions and current visions for the future.

It is important to note that the public ban on laissez fare reference to sexual matters is not reciprocated in the private sphere. "In the seclusion of their home, man and wife talk plainly about anything to do with sex, as such talk stimulates their love-play" (Aschwanden, 1982,49 [25]). In this way the severe public ban is counterbalanced by the broadmindedness in the private sphere.

The balance between the public ban and the private free-fall was the invaluable intrinsic code that propped up the concept of unhu/ubuntu. Unfortunately, "when the balance was disturbed, the pendulum swung heavily in the direction of unrestricted extreme" (Aschwanden, 1982, 50 [26]). Modernisation and westernisation removed the relevant traditional controls leaving the isolated, lonely and errant people at loggerheads with the traditional forms of communication. Xenophobic attacks in the neighbouring countries have not have spurred the need for new forms of reaching out to people. 


\section{Technological determinism and Cultural imperialism theory}

While the above lurking Garanyanya theory is vital in explaining the human behaviour in the absence of regulations and control measures it does not explain the contribution of technology in shaping social change. Marshall McLuhan's theory of the "global village" and media determinism theory (1960) becomes handy in explaining how the rendering of boundaries useless and the bridging of "time, space and distance" has motivated people to imitate others whether willingly or unwillingly as the world is perceived as one village. Hebert Schillers' cultural imperialism thesis offers a compliment to McLuhan's concepts by explaining how the Zimbabwean culture like most third world cultures is "pressured, coerced and bribed" into complying with the more "popular, dominant and attractive" Hollywood culture.

The importation of technology, both hardware and software from the advanced capitalist countries is consistent with McLuhan's view that the medium is the message. The probable 'Hollywoodising' of the virtual communities albeit in local languages is explained by the technological determinism concept. The technological determinism theory posits that the medium is the message implying thus that a medium can shape social interaction and its possible uses. The capacities of new media to make everyone an active producer of content makes the technology accountable and blameworthy for the erosion of values and morals of the Shona people.

Hebert Schiller (1976:9 [27]) asserts that cultural imperialism is ...the sum of the process by which a society is brought into the modern world system and how its dominating stratum is attracted, pressured, forced and sometimes even bribed into shaping social institutions to correspond to or even promote the values and structures of the dominating centre of the system. Pierre Bourdieu et al (1999:41 [28]) asserts that cultural imperialism rests on the power to universalise particularisms linked to a singular historical tradition by causing them to be misrecognised as such ....today numerous topics directly issuing from the intellectual confrontations relating to the social particularity of American society and of its universities have been imposed in apparently de-historicised form upon the whole planet.

Livingston A.White (2000 [29]) notes, critical theorists have coined various phrases in reference to the notion of cultural imperialism. He posits that terms such as "media imperialism" (Boyd-Barrett, 1997); "structural imperialism" (Galtung, 1977); "cultural dependency and domination" (Link 1984;Mohammadi,1995); “cultural synchronisation" (Hamelink,1983), "electronic colonialism" (McPhail,1987); "communication imperialism" (Sui-Nam Lee,1988); "ideological imperialism" and economic imperialism" (Mattleart,1994)-all relate to the same notion of cultural imperialism.

McPhail (1987 [30]) defines "Electronic colonialism as the dependency relationship established by the importation of communication hardware, foreign-produced software, along with engineers, technicians, and related information protocols, that vicariously establish a set of foreign norms, values, and expectations which, in varying degrees, may alter the domestic cultures and socialization processes."

Sui-Nam Lee [31]observed that "communication imperialism can be defined as the process in which the ownership and controlover the hardwareand software of mass media as well as other major forms of communication in one country are singly or together subjugated to the domination of another country with deleterious effects on the indigenous values, norms and culture."

Ogan [32] saw "media imperialism often described as a process whereby the United States and Western Europe produce most of the media products, make the first profits from domestic sales, and then market the products in Third World countries at costs considerably lower than those the countries would have to bear to produce similar products at home. By exporting technologies in markets in the third world the advanced states dictates the uses as technological literacy and expected uses are prescribed in package manuals.

\section{Brief theorising of social media and facebook}

Social media is an alternative means of mass communications that employs new information and communication technologies like mobile phones, ipads and internet to produce, store and distribute multi-media messaging, text messaging and mobile pictures. In this paper social media would be used to refer to popular international networking site facebook in general and in particular to Zvemubedroom and Kuisana nekunakirana Chete virtual spaces created on facebook. Social media networking according to Mhiripiri and Mutsvairo (2013:427 [33]) is usually a form of leisure that sustains interpersonal communication amongst friends, relatives, colleagues or people pursuing a common interest.

Facebook is sampled in this paper because it allows individuals and businesses to create public profiles that have many features such as user's profile. Users can connect with a page and become fans. Pages can have public messaging walls, events, photos and custom applications.

Facebook features fine-grained settings that allow individuals to control the types of profile content that your friends will be able to see. The platform is enhanced by the internet which is in many ways a paragon of democratic media, allowing anyone their say (Sutter, 2000 [34]). Mukhongo L (2013:298 [35]) asserts that "it has created an avenue for young people to express themselves and interact with each other from the comfort of their mobile phone, while in school, at home or in entertainment spots without fear of censorship or regulation. 
With everybody now able to create a mass communication channel with ease and communicate to large audiences, often cases have been raised of young people posting information on the internet with little regard to the veracity of the content being publicised (Mukhongo L 2013:298) [36]. Such inconsiderateness justifies this paper in the sense that it strives to critique whether the two sampled virtual communities are upholding denigrating the cultural values and norms of the Shona people.

\section{Sampled virtual communities on facebook: Zvemubedroom and Kuisana nekunakirana chete.}

Zvemubedroom and Kuisana nekunakirana chete virtual platforms are spaces where people in need of relationships post seeking partners, advise and counselling advise ranging from bedroom sexual techniques and skills to dealing with mundane domestic dispute cases. The platforms though prohibits under $18 \mathrm{~s}$ to participate, there are no measures to bar/restrict them. Zvemubedroom is the popular of the two and it has over 20000 fans while Kuisana neKunakirana chete has over 10000 fans/participants. Both platforms are found on facebook and indeed facebook is unprecedentedly the most popular and dominant social media platform in Zimbabwe.

The availability of the two virtual spaces on an international social media platform, Facebook, defines the producers and users of the content who are both local and foreign-based. The space is used by mostly Zimbabweans within and beyond the countries' borders. The opportunity presented by the platforms to the people seeking true love, long-lasting relationships and those seeking no-strings attached relationship are immense. As a community where the anonymity of contributors are guaranteed the language used tends to be blunt and inconsistent with the expectations of Shona peoples moral expectations.

\section{Findings and discussion}

By visiting the two virtual spaces and conducting textual analysis it was discovered that the participants on these platforms range from teens to adults over the age of 40 years. These participants identify themselves with their age and the pages' administrator acts as a mediator to those who want to meet. The page also contains lessons on sex tips for both women and men and all the followers can post their issues for debate on the platform. Among the concerns that were raised are:

- Whether long distance relationship is feasible?

- Is masturbation a $\sin$ ?

- Is sleeping with someone's wife or husband health?

- How to restore virginity?

- Prostitutes market their services.

- Is oral sex healthy?

- Who is a better, a circumcised man or uncircumcised man?

- Is it a problem to indulge in sex whilst still at school?

- There are also people seeking both long-lasting relationships and no-strings attached relationships.

- There are also concerns on how to deal with cheating spouses in particular the genital locking system termed runyoka.

- There are testimonies on sexual exploits and what generally transpires in love issues including jokes.

\section{Factors leading people to rely on social media networks for dating, relationship and counselling}

The death of the traditional water-meeting point where singles used to meet and the rapid growth of urbanisation accounts for the adaptation to new methods of dating. The breakdown or sanctions associated with other potential social places where people used to meet also accounts for the popularity of the new methods of dating.

The exposure of the current generation to western films has led many to copy the much fancied western life. In the films anti-unhu/ubuntu concepts such as speed dating and dating online are popularised and heavily marketed and like an infectious culture spreads to most parts of the world including Zimbabwe. The cultural importation of western values through being exposed to western values accounts for the desirability to use such mediums as they are perceived as 'modern'.

The use of internet-connected computers and mobile phones meant that people could converse freely in the comfort of their private spheres. Conversing freely brings with it advantages of privacy, anonymity, confidence and desire to explore one's full potential. It is these private spheres that the usually suppressed 'Garanyanya' is activated/stimulated and through the usually shunned vulgar language participants in 'Zvemubedroom' and 'Kuisana neKunakirana chete' platforms exposes their true lustful, adulterous-minded attributes. The effects of such are tremendous to the society as no-one will be partaking gatekeeping and censoring activities. All people regardless of age are participants as evidenced by posts by 15 and 16 year olds seeking advice or boosting about 
their sexual exploits.

The other factor leading people to embark on on-line dating is the recent increase in the number of people who left the country in search of greener pastures. The yearning of the 'diasporans' to find partners from home has also promoted online dating and relationship development in the cyber-space. This has meant that distance which separate people had to be bridged by meeting online. The hope of the migrants to get a potential partner from home has led to the adoption of social media as a platform to start relationships. The importation of ideas from developed countries such as America, UK and Australia has led to the quick popularity of the virtual spaces.

The people in Zimbabwe through films and television shows from the developed countries have been caught up in a desire of "not being left out". The myths of proposing love has taken a new twist where traditional forms have become unacceptable, unfashionable, backward and archaic. Misconceptions of modernity and of being time consciousness have also led to the growth and quick adoption of dating on social media.

The affordability of smart phones, ipads and laptops is key to these emerging trends thus indeed the technology is determining the new uses as argued in the technological determinism theory. The openness of social media meant that previous taboos where only men are supposed to propose in the patriarchal Shona society could be broken as this platform is a liberative sphere. The reliance on online friends rather than physical friends has also led people to seek social ideas and relationships on online platforms.

The ever recurring xenophobic attacks in countries such as South Africa and Botswana have also led people from Zimbabwe to take refuge in their mobile phones and laptops where they chat with their friendly others at home or they use the platform to seek each other in their country of exile. The fear of being victimised in a foreign land and at times the hostile gun-trotting thugs found in these countries leads people to prefer to meet special others in the usually violence-free virtual community. People who migrated to foreign countries find it easy to hide behind the technological gadgets where their safety and peace is assured. The desire to meet people from other cultures other than one's culture is also another reason why people prefer to build relationships on social media.

The other reason is that social media has become an alternative advice seeking platform where the users' secret is safe and there is no risk of being exposed. Traditionally in the African setting, families stayed close to each other and there were clear norms of who to approach in case of facing a problem. The aunts and uncles were there to offer guidance to the young and inexperienced in issues of relationship management and other social issues. The trained sociologists, counselors and psychologists are usually not trusted with personal matters thus the social media offered an alternative advice-seeking platform.

The job market has become dynamic with men and women alike going to work during the day. It thus becomes challenging to find ample time to physically go around looking for a proper partner. It thus is undisputed that the dating and online platform is a dynamic alternative platform where a person simply goes through a potential partner's profile and sees whether they are compatible or not. The risk of lies and myths just like in all relationships is always possible but the usershave to attain their goals.

There is no fear that a confidante might expose one's secret thus the platforms are conducive and sound as only strangers who have no conflict of interest offer possible solutions. It is generally taken that strangers have no bone to chew with a person asking for advice thus the social media is a transparent and confidential platform. Problems are attended by different people timeously and there is no fear of victimisation or stigmatisation thereafter as only the person who has written can take the advice they desire and sift the unwanted advice.

\section{Conclusion}

While the above uses and factors leading people to rely on social media for dating, counselling and relationship advise might seem sound and rational, the language being utilised by participants in Zvemubedroom and Kuisana nekunakirana chete virtual platforms erodes the cultural expectations of the Shona people in the sense that it is obscene, lucid vulgar. Moreso people hiding behind closed doors using pseudo names have been taking advantage of well-meaning contributions by people in need of assistance to unleash their uncontrolled tongues and to speak unpalatable words that are inconsistent with the Unhu/ubuntu expectations of the Shona people. The male and female genitalia are openly written in the vernacular, a taboo according to the unhu/ubuntu philosophy of the Shona people. The taking of advantage is surely caused by technologies which allows people to post contributions in their private spheres and indeed as expounded by the Lurking Garanyanya theory the usually suppressed bad behaviour comes in the open with the assurance that no-one would know and identify the person who posted. Unlike in the traditional sense where face to face or an intermediary negotiated for marriage relationships, the social media has provided an unrestricted, unregulated and norm- eroding sphere that is awakening the usually suppressed Garanyanya to cause untold damage.

The concept of online dating started in the developing countries and like what transpired in the modernization paradigm the Shona people are trailing behind, imitating and admiring the leading culture of the significant others abroad thus indeed complying with the cultural imperialism thesis where the ideal 
Unhu/ubuntu expectations are perceived as unacceptable in preference for the western culture. While in the western world people are subjected to vetting through for instance credit card detail requirements for a person to gain access to adult-focused content, in the third world there are no barriers to entrance thus the youths and children also consume adult-content without reservations thus leading to cultural erosion.

This paper thus recommends that dating communities should have vetting mechanisms for participants. Comments or contributions that are inconsistent with the values, beliefs and cultural expectations of the unhu/ubuntu philosophy of the Shona people should be censored. While it remains reality that online dating is here to stay measures to ensure that the humanness and good values are preserved should be enacted into law. The third world need to initiate their own social networking sites where the vernacular is easily managed and a clear ethical code of conduct and principles guiding participants in the Adult-focused virtual communities should be publicised.

\section{References}

[1] J. Crowther (ed),The Oxford Advanced Learners' Dictionary of Current English (Oxford: OUP, 1995).

[2] Standard Shona Dictionary (Gweru: Mambo Press, 1979).

[3] D. McGregor, in S. P. Robbins, Introduction to Psychology(London: OUP, 1993)

[4] T. Hobbes,Leviathan - http://oregonstate.edu/instruct/ph1302/hobbes

[5] Encyclopaedia Britannica; Thomas-Hobbes: htm (05/06/2013)

[6] The Primate Diaries: The Politics of human Nature: Thomas Hobbes [the politics of human nature Thomas Hobbes - the primate Diaries.htm] (05/06/2013).

[7] G. Williams,The Internet Encyclopaedia of Philosophy: A Peer Reviewed Academic Resource (05/06/2013).

[8] De Cive, Epistle Directory - books.google.co.zw/books?isbn =073912093x

[9] T. Hobbes, Leviathan - http://oregonstate.edu/instruct/ph1302/hobbes

[10] T.Hobbes, Leviathan - http://oregonstate.edu/instruct/ph1302/hobbes

[11] Wright, R. A. (ed),1984. 171. African Philosophy-books.google/books?isbn=1433107503

[12] E. Dube, A Tradition of Abstinence and Ritual Identity: The Ruling Sadiki Remba of Mposi in Mberengwa ( LAP Lambert Academic Publishing, 2013).

[13] H. O. Oruka, H. O. www.getcited.org/pub/100102458

[14] H. Aschwanden, Symbols of Life: An Analysis of the Consciousness of the Karanga(Gweru: Mambo Press, 1982).

[15] H. Aschwanden, Symbols of Life: An Analysis of the Consciousness of the Karanga (Gweru: Mambo Press, 1982).

[16] E. Dube, A Tradition of Abstinence and Ritual Identity: The Ruling Sadiki Remba of Mposi in Mberengwa ( LAP Lambert Academic Publishing, 2013).

[17] H. Aschwanden, Symbols of Life: An Analysis of the Consciousness of the Karanga (Gweru: Mambo Press, 1982).

[18] H. Aschwanden, Symbols of Life: An Analysis of the Consciousness of the Karanga (Gweru: Mambo Press, 1982).

[19] E. Dube, A Tradition of Abstinence and Ritual Identity: The Ruling Sadiki Remba of Mposi in Mberengwa ( LAP Lambert Academic Publishing, 2013).

[20] E. Dube, A Tradition of Abstinence and Ritual Identity: The Ruling Sadiki Remba of Mposi in Mberengwa ( LAP Lambert Academic Publishing, 2013).

[21] E. Dube, A Tradition of Abstinence and Ritual Identity: The Ruling Sadiki Remba of Mposi in Mberengwa ( LAP Lambert Academic Publishing, 2013).

[22] E. Dube, A Tradition of Abstinence and Ritual Identity: The Ruling Sadiki Remba of Mposi in Mberengwa ( LAP Lambert Academic Publishing, 2013).

[23] E. Dube, A Tradition of Abstinence and Ritual Identity: The Ruling Sadiki Remba of Mposi in Mberengwa ( LAP Lambert Academic Publishing, 2013).

[24] E. Dube, A Tradition of Abstinence and Ritual Identity: The Ruling Sadiki Remba of Mposi in Mberengwa ( LAP Lambert Academic Publishing, 2013).

[25] H. Aschwanden, Symbols of Life: An Analysis of the Consciousness of the Karanga (Gweru: Mambo Press, 1982).

[26] H. Aschwanden, Symbols of Life: An Analysis of the Consciousness of the Karanga (Gweru: Mambo Press, 1982).

[27] H. I. Schiller, Communication and cultural domination(New York: International Arts and Sciences Press, 1976).

[28] P. Bourdieu, and L. Wacquant, On the Cunning of Imperialist Reason, Theory, Culture and Society(Cambridge: Cambridge University Press, 1999).

[29] L. A. White "Reconsidering cultural imperialism theory". Transnational Broadcasting Studies (The Center for Electronic Journalism at the American University in Cairo and the Centre for Middle East Studies, St. Antony's College, Oxford) (6) 2000, pp.

[30] T. L. McPhail, Electronic colonialism: the future of international broadcasting and communication (Sage Publications, 1987).

[31] Sui-Nam Lee, Communication imperialism and dependency: A conceptual clarification (Kiuwer Academic Publications, Netherlands, 1988)

[32] Ogan, Christine (Spring 1988). "Media Imperialism and the Videocassette Recorder: The Case of Turkey". Journal of Communication, 38 (2) (Spring 1988, p94-108)

[33] Mhiripiri, N.A and Mutsvairo, B. (2013) Social media, New ICTs and the Challenges facing the Zimbabwe Democratic Process, (IGI Global Publications, 2013)

[34] G.Sutter, "Nothing new under the Sun: Old fears and new media" inInternational Journal of Law and Information Technology, 8(3),(2000, pp.338-378)

[35] L. Mukhongo, Social Media and Youth Interest in politics in Kenya (IGI-Global publications, 2013).http://en.wikipedia.org/wiki/Cultural_imperialism

[36] L. Mukhongo, Social Media and Youth Interest in politics in Kenya(IGI-Global publications, 2013).http://en.wikipedia.org/wiki/Cultural_imperialism 